\title{
Sequências de ensino investigativas envolvendo CTSA: a biomassa como tema gerador do processo de aprendizagem de conceitos químicos
}

Prislaine Pupolin Magalhães prislaine.magalhaes@unesp.br 0000-0002-1937-0226

Universidade Estadual Paulista "Júlio de Mesquita Filho", Bauru, São Paulo, Brasil.

Rebeca Castro Bighetti rebecabighetti@hotmail.com 0000-0001-9345-1713

Universidade Estadual Paulista "Júlio de Mesquita Filho", Bauru, São Paulo, Brasil.

Alexandre de Oliveira Legendre alexandre.legendre@unesp.br 0000-0002-2794-5763

Universidade Estadual Paulista "Júlio de Mesquita Filho", Bauru, São Paulo, Brasil.

Silvia Regina Quijadas Aro

Zuliani

silvia.zuliani@unesp.br

0000-0001-9523-4042

Universidade Estadual Paulista "Júlio de

Mesquita Filho", Bauru, São Paulo, Brasil.

\section{RESUMO}

Neste trabalho, compartilhamos os resultados da aplicação de uma Sequência de Ensino Investigativa (SEI) para duas turmas do primeiro ano do Ensino Médio, tendo como temática a Biomassa. Apresentaremos como a SEI promoveu a reaproximação de conteúdos específicos de Química, fomentando discussões frutuosas sobre questões CTSA (Ciência, Tecnologia, Sociedade e Ambiente) e reflexões sobre os resíduos sólidos gerados pelas usinas sucroalcooleiras, comuns na região onde os alunos residem. Mapas conceituais foram utilizados como estratégia para levantar concepções prévias e nortear as questões propostas. A partir de aparatos experimentais e uma minicaldeira previamente construída com materiais de baixo custo, grupos de alunos puderam levantar hipóteses, planejar e realizar seus experimentos. A sistematização das informações se deu a partir de relatórios, e as análises de conteúdo dos relatórios resultaram em seis categorias, das quais cinco reaproximaram conteúdos específicos em química e uma agrupou questões relacionadas ao movimento CTSA. Sabemos da necessidade de promover discussões com nossos alunos sobre possíveis fontes de energia limpa e sustentável, e observamos que a temática Biomassa foi assertiva nesse sentido, favorecendo a formação integral dos alunos. Além disso, este trabalho mostra a necessidade de repensar o currículo de química, uma vez que os conteúdos específicos não devem ser tratados de maneira linear.
\end{abstract}

PALAVRAS-CHAVE: Ensino de química. SEI. Atividades investigativas. Sequência didática. 


\section{INTRODUÇÃO}

$\mathrm{Na}$ era em que vivemos, com o avanço das tecnologias, temos observado um aumento na demanda por recursos naturais - matérias-primas e energia -, agravando ainda mais as questões ambientais. Por mais que os avanços tecnológicos nos tragam benefícios, não podemos negligenciar suas consequências, prezando sempre pela preservação dos recursos naturais a fim de buscar a sustentabilidade. Santos et al. (2015), tomando as propostas de educação libertadora de Paulo Freire como referência, relatam a importância dessa articulação entre o movimento Ciência, Tecnologia e Sociedade (CTS) sob uma perspectiva crítica de educação, ressaltando a importância de

[...] "ambientalizar" o seu currículo e que as Unidades de Aprendizagem (UA) elaboradas coletivamente no enfoque CTS favorecem a "ambientalização" na sala de aula de Ciências, intensificando a aprendizagem tanto dos alunos como dos professores, para uma leitura crítica da realidade (SANTOS et al., 2015, p. 132).

Devido à importância das questões ambientais envolvidas no conhecimento e aplicações científicas, tecnológicas e sociais, passou-se a se adotar o termo CTSA (Ciência, Tecnologia, Sociedade e Ambiente) em detrimento ao CTS (MARCONDES et al, 2016). Assumindo essa perspectiva, observamos que a temática biomassa está muito presente no cotidiano dos alunos, uma vez que a representatividade do Estado de São Paulo na dinâmica bioenergética nacional é de $45 \%$, possuindo $55 \%$ de toda área com plantações de cana-de-açúcar. Dando ênfase especial, para a região de Bauru, onde esta atividade foi realizada, destaca-se a existência de 12 usinas produtoras de açúcar e álcool, sendo responsável por $12 \%$ da produção de álcool do estado de São Paulo (RAMOS; NACHILUK, 2017).

A moagem da cana produz grande quantidade de bagaço, que, geralmente, destina-se à geração de bioeletricidade, tanto para alimentar o processo de produção de açúcar e etanol, como para abastecer a rede de distribuição de energia (IEA, 2017). A partir dessa temática, pode-se refletir e debater sobre as possíveis aplicações e/ou destinação dos resíduos sólidos gerados com base em suas propriedades químicas e físico-químicas.

No Brasil, podemos destacar o grupo de pesquisa CENBIO - Centro Nacional de Referência em Biomassa ${ }^{1}$, localizado na Universidade de São Paulo - USP, como referência nos estudos dessa temática. Pesquisadore desse grupo destacam que a Biomassa é utilizada como fonte de energia primária para cerca de 2,4 bilhões de pessoas em países em desenvolvimento (GBio, 2019). Dividem as tecnologias envolvidas no uso da biomassa, como sendo tradicionais (combustão direta), tecnologias aperfeiçoadas (fornos) e tecnologias modernas com as "biomassas modernas" (produção de eletricidade e biocombustíveis). A biomassa pode ser considerada fonte renovável de energia quando a matéria-prima é originada de reflorestamento.

O ensino de ciências deve primar pela contextualização, com os conhecimentos escolares se relacionando com o contexto pessoal do aluno (Santos e Schnetzler, 1997), possibilitando uma formação crítica, para que os futuros cidadãos possam fazer diferença na comunidade em que vivem. Assim, optamos por utilizar a temática Biomassa como tema gerador. Este trabalho propõe um modelo de Sequências de Ensino Investigativa (SEI) fundamentadas em Carvalho 
(2018) e Cañal (1997). Segundo os autores, podemos definir uma SEl como uma sequência de aulas sobre um tópico do programa escolar, partindo do planejamento como etapa fundamental, e seguida da organização do material disponível para executar as atividades experimentais, levando-se em consideração o prévio levantamento de hipóteses.

Carvalho (2018) defende que, nas SEl, o professor não é único detentor do saber, devendo atuar como mediador do processo de aprendizagem, e aprendendo com as discussões trazidas pelos seus alunos durante o seu desenvolvimento. Nesse tipo de atividade, o aluno deve se engajar para resolver um problema experimental, com os recursos e aparatos disponíveis, não sendo limitados por roteiros experimentais preestabelecidos. A autora enfatiza que as etapas de pesquisa, planejamento e levantamento de hipóteses são muito importantes para o aprendizado, estimulando discussões dos alunos com seus pares e o professor, além de favorecer o desenvolvimento do pensamento científico crítico. Além disso, a proposta ensina os alunos a trabalharem e elaborarem conclusões em equipe.

De acordo com Carvalho (2018), as SEI são divididas em quatro etapas. A primeira etapa consiste na contextualização e proposição do problema pelo professor, seguida da distribuição do material experimental. Nesta etapa, os alunos deverão ser divididos em grupos para se apropriarem dos aparatos experimentais, bem como da questão problema. Na segunda etapa, ocorre o levantamento de hipóteses, visando à resolução dos problemas por meio de planejamentos elaborados pelos grupos de alunos. Neste momento, o professor deve se preocupar apenas com que se as questões problematizadoras e norteadoras foram compreendidas. A terceira etapa é a etapa de sistematização dos conhecimentos elaborados pelo grupo. Nesta etapa, o professor auxilia os alunos na sistematização dos novos conhecimentos. Finalmente, temos a quarta etapa, chamada pela autora de etapa de desenhar ou escrever. Etapa de aprendizagem individual, após aprendizagem social com os pares e professor.

Como já descrito anteriormente, o ponto de partida de uma SEl é uma situação problematizadora contextualizada. Motokane (2015) descreve que o problema inicial proposto é crucial, pois, por meio dele, o professor provoca o interesse dos seus alunos, instigando-os a buscar respostas e fazendo-os elaborar hipóteses explicativas. Adotando esta metodologia, podemos ir além do conteúdo explorado pelo problema, podendo realizar uma contextualização social (CARVALHO, 2018). Desta maneira, o problema inicial na atividade investigativa não pode ser uma questão qualquer, e estar contido na cultura social dos alunos.

Cañal (1997) também sistematiza o ensino por investigação, argumentando que o professor deve oferecer condições para que os alunos resolvam problemas e busquem relações causais entre variáveis para explicar o fenômeno observado, por meio do uso de raciocínio do tipo hipotético-dedutivo. Desta maneira, os alunos utilizam os conhecimentos prévios para construir novos, tem liberdade para expor suas próprias ideias.

Deste modo, a inserção de novas informações ou ideias serão alicerçadas no que os alunos já sabem, ou seja, o conhecimento científico evolui a partir dos conhecimentos já estruturados na sua estrutura cognitiva, estando de acordo com a teoria de David Ausubel (NOVAK, 2002). Nesse sentido, podemos contar com o emprego de mapas conceituais, que são recursos de aprendizagem que permitem 
não somente diagramar como determinados conceitos estão interligados, como podem ser utilizados para o levantamento de conhecimentos prévios - de um aluno ou grupo de alunos -, a partir dos quais se dará a assimilação dos conhecimentos científicos, caracterizando uma aprendizagem verdadeiramente significativa (Moreira, 2011).

Favila e Adaime (2013) relatam que, principalmente no Ensino Médio, muitas escolas ainda enfatizam a memorização de conteúdos através de aulas expositivas dialogadas, seguindo o livro didático ou apostilas. A BNCC (Base Nacional Comum Curricular) menciona a importância da inserção de atividades que visem o protagonismo dos alunos, como esta proposta. Segundo o documento, deve-se propor desafios e problemas abertos e contextualizados, visando estimular a curiosidade e a criatividade na elaboração de procedimentos e na busca de soluções de natureza teórica e experimental (BRASIL, 2017).

A SEI descrita neste trabalho é um modelo de como aproximar os currículos propostos pela BNCC ao cotidiano dos alunos, propondo uma contextualização crítica e reflexiva por meio de discussões associadas ao movimento CTSA. Usando a análise de conteúdo, descrita por Bardin (2011) e realizada a posteriori, pudemos levantar quais conceitos químicos e concepções CTSA estão inseridas na SEI proposta neste trabalho. Assumimos que a temática Biomassa pode contribuir para a formação de alunos mais conscientes e críticos.

\section{METODOLOGIA}

\section{Descrição das etapas desenvolvidas}

A atividade foi realizada concomitantemente com duas turmas - as quais chamaremos de sala 1 e sala 2 - do primeiro ano de uma escola pública, totalizando 68 alunos. Os alunos são estudantes de um curso diurno de Ensino Médio integrado com Curso Técnico em Informática. A disciplina Química, na qual a atividade foi realizada, ter três aulas semanais, e a escola dispõe de laboratório didático. A SEI aplicada foi detalhadamente planejada conforme descrito por Carvalho (2018). O Quadro 1 sintetiza as quatro aulas que foram realizadas.

Inicialmente, realizamos o momento 1 , quando foi construído, em grupo, um mapa conceitual. Os alunos realizaram um "brainstorm", durante o qual expuseram seus conhecimentos sobre o assunto e suas relações. A questão focal foi: o que é Biomassa? Dentro dessa questão, os alunos mencionaram seus conhecimentos, juntamente aos conteúdos de química aprendidos anteriormente. Usando esse recurso, pudemos realizar o levantamento das concepções prévias dos estudantes sobre a temática biomassa e suas associações. Para edição do Mapa Conceitual, foi utilizado o programa CmapTools ${ }^{2}$. No final da aula, para um momento de sensibilização, os alunos assistiram a reportagem em vídeo "Biomassa já responde por quase $10 \%$ de toda a matriz energética do Brasil" 3 (TRIGUEIRO, 2014).

Em um segundo momento, uma aula experimental investigativa de 140 minutos foi realizada com os alunos distribuídos em grupos de 4 ou 5 integrantes (Quadro 1), utilizando uma "minicaldeira". Iniciamos a aula com a distribuição do material experimental: minicaldeira, bagaço de cana-de-açúcar seco, fósforos, termômetro, copo de vidro (ou béquer), fita-teste para piscina (com o frasco original para uso da escala comparativa), mini balança digital de precisão, água 
destilada e outros materiais que os alunos julgaram necessário dentro da proposta. Os seguintes questionamentos norteadores foram previamente escritos na lousa: O que acontece com o bagaço e a água após a queima? Há alguma mudança na queima com a abertura fechamento das janelas? Por quê? Quais são as características da fumaça? Há resíduos? Quais são as suas propriedades? Como a queima da biomassa pode ser utilizada para gerar energia? É um processo sustentável?

Quadro 1 - Quadro sintético sistematizado de ações da SEI proposta neste trabalho

\begin{tabular}{|c|c|c|}
\hline Momentos & Ações & Descrição \\
\hline 1 (50 minutos) & $\begin{array}{l}\text { Concepções } \\
\text { prévias } \\
\text { (sala de aula) }\end{array}$ & $\begin{array}{l}\text { Levantamento de concepções prévias, através de } \\
\text { mapas conceituais. } \\
\text { Reportagem: Biomassa já responde por quase } \\
\text { 10\% de toda a matriz energética do Brasil }\end{array}$ \\
\hline \multirow{4}{*}{$\begin{array}{l}2 \text { Aula } \\
\text { experimental } \\
\text { investigativa } \\
\text { (140 minutos) }\end{array}$} & Problematização & $\begin{array}{l}\text { Etapa de e proposição do problema pelo } \\
\text { professor, neste caso através de questões } \\
\text { propostas na lousa e distribuição do material } \\
\text { experimental. Momento de levantar hipóteses e } \\
\text { planejar os testes experimentais. }\end{array}$ \\
\hline & $\begin{array}{l}\text { Resolução do } \\
\text { problema }\end{array}$ & $\begin{array}{l}\text { Etapa de resolução do problema pelos alunos. } \\
\text { Momento de testar hipóteses realizando testes } \\
\text { experimentais. }\end{array}$ \\
\hline & Sistematização & $\begin{array}{c}\text { Recolher o aparato experimental e estimular o } \\
\text { debate entre os grupos, para que através de } \\
\text { argumentação científica respondam as questões } \\
\text { propostas. }\end{array}$ \\
\hline & Escrever & $\begin{array}{l}\text { Responder as questões em grupo em folha de } \\
\text { papel almaço a ser entregue pelo professor. }\end{array}$ \\
\hline 3 (50 minutos) & $\begin{array}{l}\text { Atividade de } \\
\text { síntese }\end{array}$ & $\begin{array}{l}\text { Discussão final dos conteúdos, envolvendo } \\
\text { abordagens CTSA. }\end{array}$ \\
\hline
\end{tabular}

Fonte: Autor (2019).

Os alunos foram orientados a responderem as questões utilizando o aparato experimental disponibilizado na bancada. Assim, os alunos levantaram hipóteses e baseado nelas, realizaram o planejamento experimental, sempre através de discussão em grupo. Através de atividades experimentais, observaram fenômenos e juntos responderam os questionamentos. 
Figura 1 - Minicaldeira construída com latas de alimentos. A: materiais usados na construção, B: "forno" com as janelas de oxigenação abertas, e C: caldeira montada com termômetro e uma fita-teste umedecida posicionada em um ponto de saída de gases
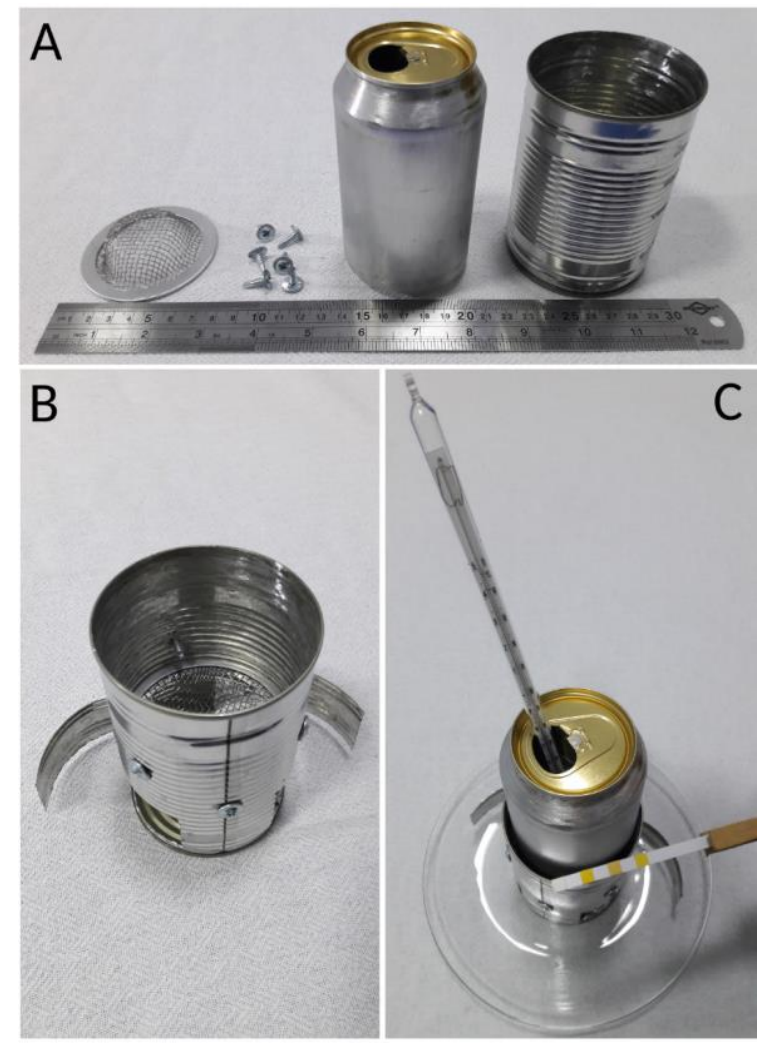

Fonte: Autora (2019).

A minicaldeira foi previamente construída pela professora responsável usando uma lata de ferro - em cuja base foram abertas duas janelas para oxigenação, e na qual foram inseridos dois trios de parafusos em duas alturas diferentes, sendo um para apoiar a tela sobre a qual se coloca a biomassa, e o outro para apoiar o recipiente com água -, uma lata de alumínio, uma tela para ralo e seis parafusos. Foram apresentadas recomendações para a utilização da minicaldeira, tais como o local correto da queima do bagaço, o compartimento da água e como apoiar o termômetro no lacre de alumínio. As janelas de ventilação poderiam ficar abertas ou fechadas, dependendo da decisão tomada na discussão realizada pelos grupos. Por se tratar de uma atividade experimental investigativa, essa atividade não teve roteiro preestabelecido. Assim, os grupos realizaram seus planejamentos a partir de suas hipóteses, e cada equipe utilizou quantidades de material e reagentes que julgaram necessário.

Terminada a atividade experimental, o material experimental foi recolhido e se iniciou a etapa de sistematização dos conhecimentos. Neste momento, foram retomadas as questões dispostas no quadro e discutidas a partir dos resultados experimentais em grupo, que foram descritas pelos grupos na forma de relatórios.

No terceiro e último momento, a professora devolveu aos alunos os relatórios corrigidos, iniciando-se uma discussão em sala de aula a respeito da atividade desenvolvida, associando-a com os conteúdos químicos ministrados. Com a correção, ocorreu o levantamento dos erros e assim, pudemos enfatizar a discussão final baseada nas dificuldades das turmas. Sempre que pertinentes, as 
questões sobre tecnologia, sociedade e ambiente foram introduzidas, visando incentivar as reflexões propostas no movimento CTSA. A avaliação foi processual e formativa, durante todas as etapas desenvolvidas.

\section{METODOLOGIA DA PESQUISA}

Trata-se de uma pesquisa qualitativa descritiva, baseada na análise das questões propostas em aula prática respondidas na forma de relatório pelos grupos de alunos. Obtivemos um total de 15 relatórios, previamente transcritos. Destacamos que os 15 grupos foram representados ao longo desse trabalho de G1 a G15, como forma a manter o anonimato dos estudantes.

A metodologia de análise utilizada para tratamento dos dados foi a Análise de Conteúdo segundo Bardin (2011), de acordo com a qual os extratos de textos representativos provenientes dos questionários foram as unidades de sentido identificadas a posteriori, que originaram as subcategorias conceituais. 0 agrupamento das subcategorias resultou em seis categorias finais (Quadros 2 a 8): Transformações da matéria; Propriedades específicas da matéria; Transformações Químicas; Físico-Químicas; pH e CTSA.

\section{RESULTADOS E DISCUSSÃO}

Para realizar o levantamento das concepções prévias, no início da SEI foi elaborado um Mapa Conceitual. Estes podem funcionar como organizadores prévios, os quais, segundo Moreira (2011), são instrumentos facilitadores da aprendizagem, pois permitem que o aluno relacione as novas informações com a estrutura cognitiva preexistente e, a partir daí, assimilar novos conceitos. Desta maneira, selecionamos a forma mais adequada de como trabalhar os conteúdos e quais estratégias de ensino. A Figura 2 apresenta o mapa conceitual editado obtido no levantamento das concepções prévias apontadas pelos alunos da sala 1.

Figura 2 - Mapa conceitual obtido no levantamento de concepções prévias apontadas pelos alunos da sala 1

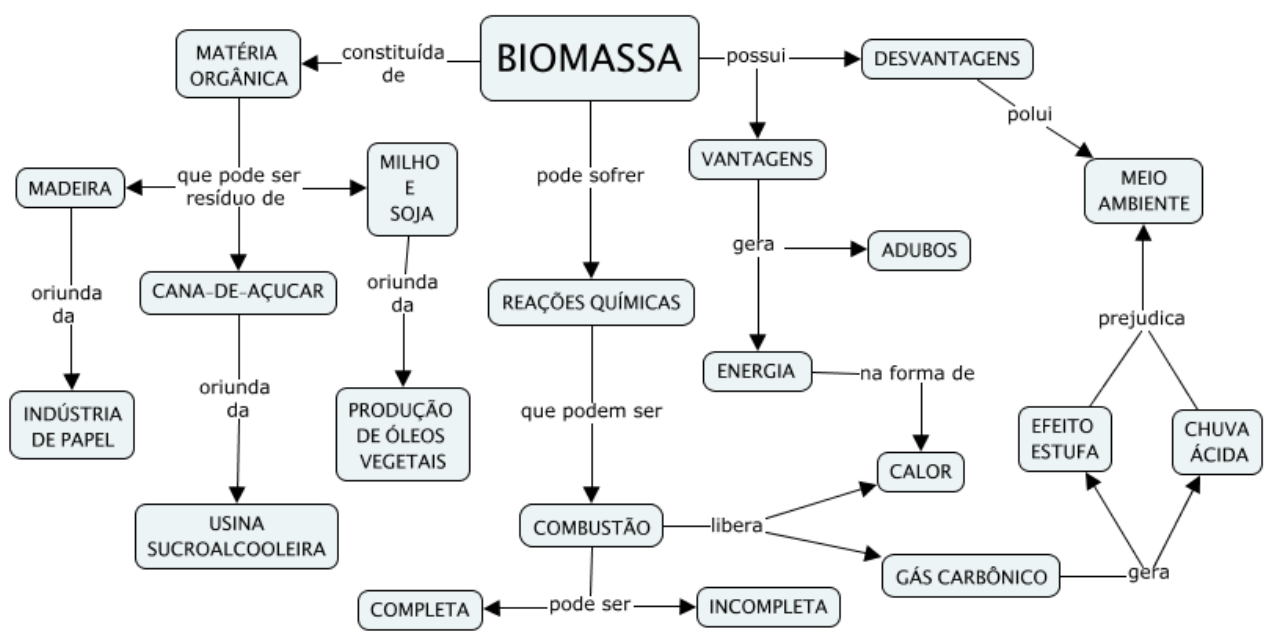

Fonte: Autora (2019). 
Em um segundo momento, os grupos se dirigiram ao laboratório, onde encontraram, na lousa, as questões problematizadoras, e, sobre a bancada, o material experimental organizado. Assim, levantaram hipóteses, planejaram e realizaram experimentos, sem maiores intercorrências. De maneira geral, após realizarem a pesagem do bagaço de cana-de-açúcar seco, os grupos o inseriram dentro da minicaldeira. A massa média utilizada pelos grupos foi de dois gramas. Em seguida, colocaram o termômetro e adicionaram água à lata de alumínio, como mostrado na Figura 1 A. Então, atearam fogo no bagaço seco, observaram a queima e verificaram o caráter ácido da fumaça com o papel indicador (Figura 3 A). Os alunos se incomodaram um pouco com o cheiro da fumaça e, neste momento, puderam refletir sobre a qualidade do ar e sobre as condições de trabalho dos trabalhadores rurais, nas usinas termoelétricas e nas carvoarias. De maneira geral, os grupos avaliaram a variação da temperatura da água e da massa do resíduo gerado. Utilizando o papel indicador de $\mathrm{pH}$, concluíram que as cinzas tinham caráter alcalino (Figura 3B).

Figura 3 - Medições de $\mathrm{pH}$. A: fita-teste umedecida exposta à fumaça resultante da queima, e B: fita-teste colocada em uma mistura de água e cinzas remanescentes da queima da biomassa

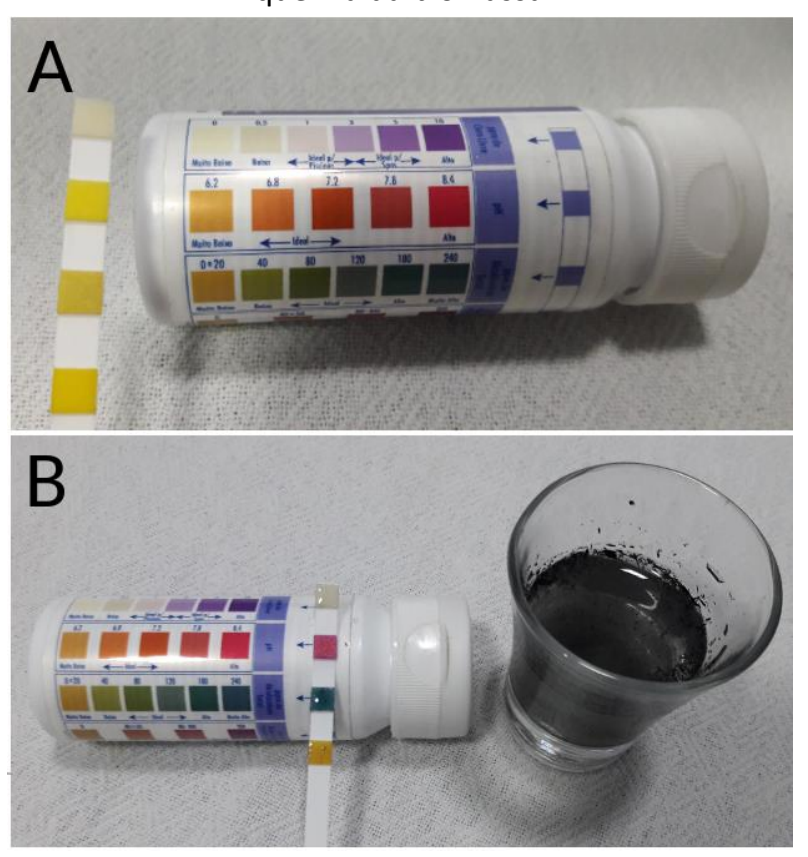

Fonte: Autora (2019).

No final da SEl, foram retomadas as questões norteadoras propostas no quadro e discutidas a partir dos resultados experimentais. Observou-se, nesse momento, o início do desenvolvimento de atitudes científicas com o levantamento de hipóteses, obtenção dos dados empíricos e a sistematização de evidências, que foram registradas nos relatórios. Foi realizada a Análise de Conteúdo (BARDIN, 2011) dos relatórios contendo as respostas dos 15 grupos participantes. Inicialmente, realizamos a pré-leitura, definimos as unidades de sentido, as subcategorias e, por fim, as categorias (Quadros 2 a 7). Os erros também foram agrupados (Quadro 8).

Durante a aplicação da SEI, pudemos observar que praticamente todos os grupos tiveram autonomia ao utilizar a balança, fazendo associação com as Leis 
Ponderais. Os alunos mediram a massa do bagaço e da água, antes e depois do experimento, o que pode ser observados no Quadro 2. Alguns grupos de alunos chegaram a mencionar a Lei de Lavoisier, conteúdo que foi abordado no primeiro bimestre. Como esta atividade foi proposta no quarto bimestre, isso indica uma aprendizagem significativa, pois o conhecimento foi associado e aplicado em um outro contexto (MOREIRA, 2011).

Com relação às propriedades específicas da matéria, as propriedades organolépticas são as primeiras a serem mencionadas de maneira geral, provavelmente por serem menos abstratas (Quadro 3).

Quadro 2-Categoria 1: Transformações da matéria

\begin{tabular}{|c|c|c|c|}
\hline $\begin{array}{l}\text { Subcategoria } \\
\text { (Conceitual) }\end{array}$ & $\begin{array}{l}\text { Número de } \\
\text { menções }\end{array}$ & Grupos & $\begin{array}{l}\text { Extratos de textos } \\
\text { representativos apontados } \\
\text { (Unidades de Sentido) }\end{array}$ \\
\hline Leis Ponderais & 18 & $\begin{array}{c}\text { G1; G2; G3; } \\
\text { G4; G4; G5; } \\
\text { G6; G6; G7; } \\
\text { G8; G10; G11; } \\
\text { G12; G13; } \\
\text { G14; G14; } \\
\text { G15; G15 }\end{array}$ & $\begin{array}{c}\text { [já em relação água ela chega a } \\
80^{\circ} \mathrm{C} \text { e acaba evaporando } \\
\text { diminuindo sua massa] } \\
\text { [com o aumento da temperatura } \\
\text { no sistema aberto, a temperatura } \\
\text { da água aumentou, mudando de } \\
\text { estado físico [...] gasoso, mas não } \\
\text { ocorreu perda de massa, segundo } \\
\text { Lavoisier] }\end{array}$ \\
\hline
\end{tabular}

Fonte: Autora (2019).

Os conceitos sobre as propriedades específicas da matéria, como inflamabilidade, condutividade, solubilidade e densidade, foram citados, como podemos observar no Quadro 3. Dois grupos também mencionaram as propriedades periódicas dos metais alcalinos ao observar a alcalinidade das cinzas, e um grupo foi além, mencionando inclusive a origem da palavra álcali.

Quadro 3 - Categoria 2: Propriedades específicas da matéria

\begin{tabular}{|c|c|c|c|}
\hline $\begin{array}{l}\text { Subcategoria } \\
\text { (Conceitual) }\end{array}$ & $\begin{array}{l}\text { Número de } \\
\text { menções }\end{array}$ & Grupos & $\begin{array}{l}\text { Extratos de textos } \\
\text { representativos apontados } \\
\text { (Unidades de Sentido) }\end{array}$ \\
\hline $\begin{array}{l}\text { Propriedades } \\
\text { organolépticas }\end{array}$ & 16 & $\begin{array}{c}\text { G1; G2; G2; } \\
\text { G3; G3; G6; } \\
\text { G6; G6; G7; } \\
\text { G8; G10; G10; } \\
\text { G11; G12; } \\
\text { G14; G15; G15 }\end{array}$ & $\begin{array}{l}\text { [as cinzas têm características: a } \\
\text { cor preta e é inflamável] } \\
\text { [A fumaça tem cor clara e odor } \\
\text { forte e incômodo] }\end{array}$ \\
\hline Inflamabilidade & 3 & G6; G7; G15 & $\begin{array}{c}\text { [no entanto, sua quantidade } \\
\text { mostra que o combustível é } \\
\text { altamente inflamável] } \\
\text { [as cinzas têm como } \\
\text { características uma cor preta, com } \\
\text { propriedades básicas } \\
\text { (comprovadas com o papel } \\
\text { indicador universal) e pode ser } \\
\text { inflamável] }\end{array}$ \\
\hline
\end{tabular}




\begin{tabular}{|c|c|c|c|}
\hline Condutividade & 2 & G3; G6 & $\begin{array}{l}\text { [o alumínio é bom condutor de } \\
\text { calor] } \\
\text { [acaba aquecendo o alumínio da } \\
\text { lata que é um bom condutor de } \\
\text { calor e, consequentemente, } \\
\text { aquece a água também] }\end{array}$ \\
\hline Solubilidade & 2 & G5; G12 & $\begin{array}{c}\text { [as cinzas são solúveis em água] } \\
\text { [as cinzas são parcialmente } \\
\text { solúveis em água] }\end{array}$ \\
\hline Densidade & 3 & G1; G8; G12 & $\begin{array}{c}\text { [a fumaça era densa e } \\
\text { esbranquiçada] } \\
\text { [a fumaça é branca densa e ácida] }\end{array}$ \\
\hline $\begin{array}{c}\text { Propriedades } \\
\text { Periódicas }\end{array}$ & 2 & G13; G15 & $\begin{array}{l}\text { [o resíduo básico tem esse caráter } \\
\text { por causa dos metais alcalinos que } \\
\text { não são eliminados na combustão] } \\
\text { [afinal, substâncias que contém } \\
\text { metais (como aqueles que } \\
\text { compõem a cana) tem caráter } \\
\text { básico. Daí vem o nome "metais } \\
\text { alcalinos" pois a palavra álcali } \\
\text { descreve substâncias básicas] }\end{array}$ \\
\hline
\end{tabular}

Fonte: Autora (2019).

Com relação ao conteúdo Transformações Químicas, sete grupos de alunos consideraram o fenômeno como uma reação de combustão incompleta, principalmente devido à presença de resíduo. Neste conceito, provavelmente, os alunos fizeram uma associação com os resíduos devido à presença de uma questão que foi apresentada que enfatizava o mesmo aspecto, ou seja, sendo provavelmente respostas com influências indutivas. Quatro grupos também mencionaram o fenômeno de liberação de gás associado a transformações químicas, como pode ser observado no Quadro 4.

Quadro 4 - Categoria 3: Transformações Químicas

\begin{tabular}{|c|c|c|c|}
\hline $\begin{array}{c}\text { Subcategoria } \\
\text { (Conceitual) }\end{array}$ & $\begin{array}{l}\text { Número de } \\
\text { menções }\end{array}$ & Grupos & $\begin{array}{c}\text { Extratos de textos representativos } \\
\text { apontados } \\
\text { (Unidades de Sentido) }\end{array}$ \\
\hline Combustão & 1 & G4 & $\begin{array}{l}\text { [Devido a combustão, o combustível, } \\
\text { ou seja, o bagaço se transformou em } \\
\mathrm{CO}_{2} \text { na presença de gás oxigênio] }\end{array}$ \\
\hline $\begin{array}{l}\text { Combustão } \\
\text { incompleta }\end{array}$ & 7 & $\begin{array}{l}\text { G2; G3; G6; } \\
\text { G8; G13; } \\
\text { G13; G15 }\end{array}$ & $\begin{array}{c}\text { [é uma reação de combustão } \\
\text { incompleta] } \\
\text { [deixou resíduos sólidos, por causa } \\
\text { de uma combustão incompleta] } \\
\text { [a fumaça possui cheiro diferente e é } \\
\text { mais inflamável] }\end{array}$ \\
\hline Liberação de gás & 4 & $\begin{array}{c}\text { G3; G5; G6; } \\
\text { G11 }\end{array}$ & $\begin{array}{l}\text { [a maior parte se transformou em } \\
\text { CO2 e gerou um resíduo do bagaço] } \\
\text { [o bagaço se transformou em cinzas, } \\
\text { devido a liberação de gás carbônico] }\end{array}$ \\
\hline
\end{tabular}

Fonte: Autora (2019). 
Neste conteúdo o grupo G13 mencionou que "a fumaça possui cheiro diferente e é mais inflamável", assim podemos nos perguntar: o grupo realmente compreendeu que a combustão incompleta produz $\mathrm{CO}$ que é um gás altamente inflamável e tóxico? Questões desta natureza foram discutidas no momento de síntese conforme proposto por Carvalho (2018).

Quadro 5-Categoria 4: Físico-Química

\begin{tabular}{|c|c|c|c|}
\hline $\begin{array}{l}\text { Subcategoria } \\
\text { (Conceitual) }\end{array}$ & $\begin{array}{l}\text { Número de } \\
\text { menções }\end{array}$ & Grupos & $\begin{array}{c}\text { Extratos de textos } \\
\text { representativos apontados } \\
\text { (Unidades de Sentido) }\end{array}$ \\
\hline Cinética química & 6 & $\begin{array}{l}\text { G3; G4; G5; } \\
\text { G6; G8; G14 }\end{array}$ & $\begin{array}{l}\text { [com a abertura pode entrar mais } \\
\text { gás oxigênio tornando a queima } \\
\text { mais rápida] } \\
\text { [a abertura da janela aumentou a } \\
\text { velocidade de queima] }\end{array}$ \\
\hline $\begin{array}{l}\text { Efeito da } \\
\text { concentração dos } \\
\text { reagentes na } \\
\text { velocidade de } \\
\text { reações }\end{array}$ & 14 & $\begin{array}{c}\text { G1; G2; G3; } \\
\text { G4; G5; G6; } \\
\text { 7G; G8; G9; } \\
\text { G11; G12; } \\
\text { G13; G14; G15 }\end{array}$ & $\begin{array}{l}\text { [há maior entrada de oxigênio } \\
\text { quando a janela está aberta] } \\
\text { [com as janelas abertas, há uma } \\
\text { maior oxigenação] }\end{array}$ \\
\hline $\begin{array}{l}\text { Termoquímica - } \\
\text { Energia de } \\
\text { ativação }\end{array}$ & 1 & G1 & $\begin{array}{c}\text { [o bagaço em calor reage com o } \\
\text { oxigênio] }\end{array}$ \\
\hline $\begin{array}{c}\text { Termoquímica - } \\
\text { Reações } \\
\text { Exotérmicas }\end{array}$ & 4 & G1; G3; G4; G6 & $\begin{array}{c}\text { [Devido a combustão, o } \\
\text { combustível, ou seja, o bagaço se } \\
\text { transformou em CO2 e liberou } \\
\text { energia térmica, deixando alguns } \\
\text { resíduos] } \\
\text { [através da combustão do bagaço } \\
\text { de cana, o calor é liberado para } \\
\text { aquecer uma caldeira com água e } \\
\text { virar vapor] }\end{array}$ \\
\hline $\begin{array}{c}\text { Transformação de } \\
\text { energia }\end{array}$ & 8 & $\begin{array}{l}\text { G1; G4; G4; } \\
\text { G5; G6; G7; } \\
\text { G10; G12 }\end{array}$ & $\begin{array}{l}\text { [que por sua vez irá evaporar e } \\
\text { girar a turbina, transformando a } \\
\text { cinética em elétrica.] } \\
\text { [a queima fara energia térmica, } \\
\text { que se transforma em energia } \\
\text { cinética, que logo em seguida se } \\
\text { transforma em energia elétrica] }\end{array}$ \\
\hline
\end{tabular}

Fonte: Autora (2019).

Podemos observar que o conceito de $\mathrm{pH}$ estava na estrutura cognitiva dos alunos (Quadro 6), uma vez que todos os grupos classificaram a fumaça como ácida e as cinzas como básicas. Também foram observados conceitos específicos de físico-química. Apesar dos alunos ainda estarem cursando o primeiro ano do Ensino Médio, conceitos envolvendo questões de Cinética Química, com ênfase na concentração dos reagentes, foram citados por praticamente todos os grupos. Alguns grupos também classificaram a reação como exotérmica e oito grupos mencionaram conceitos de transformação de energia. 
Quadro 6-Categoria 5: pH

\begin{tabular}{|c|c|c|c|}
\hline $\begin{array}{c}\text { Subcategoria } \\
\text { (Conceitual) }\end{array}$ & $\begin{array}{c}\text { Número de } \\
\text { menções }\end{array}$ & Grupos & $\begin{array}{l}\text { Extratos de textos } \\
\text { representativos apontados } \\
\text { (Unidades de Sentido) }\end{array}$ \\
\hline Acidez & 15 & $\begin{array}{r}\text { G1; G1; G2; } \\
\text { G3; G3; G4; } \\
\text { G6; G8; G8; } \\
\text { G9; G10; G11; } \\
\text { G13; G14; G15 }\end{array}$ & $\begin{array}{l}\text { [A fumaça, composta } \\
\text { principalmente por CO2 tem } \mathrm{pH} \\
\text { ácido] } \\
\text { [a fumaça tem caráter ácido (pH } \\
\text { estimado 4)] }\end{array}$ \\
\hline Alcalinidade & 16 & $\begin{array}{l}\text { G1; G2; G2; } \\
\text { G3; G4; G5; } \\
\text { G6; G7; G7; } \\
\text { G8; G8; G11; } \\
\text { G12; G13; } \\
\text { G15; G15 }\end{array}$ & $\begin{array}{c}\text { [observamos que o } \mathrm{pH} \text { das cinzas } \\
\text { é aproximadamente } 10, \text { portanto } \\
\text { é uma base] } \\
\text { [o pH obtido nas cinzas tem } \\
\text { caráter básico] }\end{array}$ \\
\hline
\end{tabular}

Fonte: Autora (2019).

Com relação aos conceitos apontados relacionados às questões CTSA, o pensamento crítico dos estudantes foi evidenciado pelo fato de onze grupos terem mencionado a geração de resíduos pela aula prática, como podemos observar no Quadro 7 (SANTOS, 2008; SANTOS; MORTIMER, 2001). Cerca de metade dos grupos mencionou a importância de se reaproveitar a biomassa. Segundo Gouveia (2012), além da relação com a tecnologia, deve-se relembrar que, nos últimos anos, questões ambientais passaram a fazer parte da vida de todos nós. A proximidade dos problemas ambientais da vida dos alunos é uma característica que favorece o trabalho no que diz respeito à formação do educando enquanto cidadão que interage com o mundo e é capaz de transformar seu entorno (BORGES; BENETTI, 2015; GOUVEIA, 2012). Neste sentido, sete grupos também relataram problemas ambientais com relação a produção de gás carbônico, e apenas dois grupos relacionaram o mesmo com o efeito estufa.

Quadro 7 - Categoria 6: CTSA

\begin{tabular}{|c|c|c|c|}
\hline $\begin{array}{l}\text { Subcategoria } \\
\text { (Conceitual) }\end{array}$ & $\begin{array}{l}\text { Número de } \\
\text { menções }\end{array}$ & Grupos & $\begin{array}{l}\text { Extratos de textos } \\
\text { representativos apontados } \\
\text { (Unidades de Sentido) }\end{array}$ \\
\hline Efeito estufa & 7 & $\begin{array}{c}\text { G3; G3; G6; } \\
\text { G4; G4; G6; G7 }\end{array}$ & $\begin{array}{l}\text { [produz muito gás carbônico, o } \\
\text { que contribui para o efeito estufa] } \\
\text { [gera muito gás carbônico e acaba } \\
\text { contribuindo para o aumento do } \\
\text { efeito estufa] [é prejudicial a } \\
\text { natureza por causa da emissão de } \\
\qquad \mathrm{CO}_{2} \text { ] } \\
\text { [é um processo que possui prós e } \\
\text { contras, pois é um recurso } \\
\text { renovável, porém libera } \mathrm{CO}_{2} \text { ] }\end{array}$ \\
\hline Resíduos & 11 & $\begin{array}{l}\text { G1; G3; G3; } \\
\text { G4; G4; G5; } \\
\text { G6; G8; G11; } \\
\text { G13; G14 }\end{array}$ & $\begin{array}{l}\text { [ainda observamos resíduos de } \\
\text { bagaço] } \\
\text { [a biomassa é consumida na } \\
\text { reação, porém deixa resíduos de } \\
\text { carbono] }\end{array}$ \\
\hline
\end{tabular}




\begin{tabular}{|c|c|c|c|}
\hline Reaproveitar & 6 & $\begin{array}{c}\text { G2; G9; G11; } \\
\text { G12; G13; G15 }\end{array}$ & $\begin{array}{c}\text { [queima a biomassa pode ser } \\
\text { utilizada nas indústrias } \\
\text { termoelétricas] } \\
\text { [a biomassa pode ser utilizada } \\
\text { como combustível para geração } \\
\text { de energia nas termoelétricas] }\end{array}$ \\
\hline Sustentabilidade & 8 & $\begin{array}{l}\text { G2; G3; G5; } \\
\text { G8; G11; G12; } \\
\text { G14; G15 }\end{array}$ & $\begin{array}{l}\text { [concluímos que a biomassa é } \\
\text { Sustentável podendo ser } \\
\text { reabastecida, porém não é } \\
\text { totalmente limpa] } \\
\text { [é um processo sustentável e } \\
\text { renovável, mas não é totalmente } \\
\text { limpa] }\end{array}$ \\
\hline Energia Limpa & 4 & $\begin{array}{c}\text { G2; G3; G8; } \\
\text { G15 }\end{array}$ & $\begin{array}{l}\text { [porém seu emprego não é } \\
\text { considerado uma fonte de energia } \\
\text { limpa] } \\
\text { [é sustentável, porém não é limpa, } \\
\text { devido a grande emissão de CO2] }\end{array}$ \\
\hline
\end{tabular}

Fonte: Autora (2019).

Os resultados apontados no Quadro 7 estão de acordo com a BNCC (BRASIL, 2017), que destacam a importância do Ensino de Química voltado para formação do cidadão. Este documento reitera a importância do aprendizado contextualizado envolvendo diferentes vertentes e retomada de conceitos, proporcionando aos alunos uma compreensão das transformações químicas de forma abrangente e integrada, principalmente no que diz respeito às questões CTSA, para que, num futuro próximo, possam tomar decisões corretas e conscientes (SANTOS; MORTIMER, 2000). Sendo assim, observamos que os grupos compreenderam o conceito e a importância dos termos sustentabilidade (8 grupos) e energia limpa (4 grupos) na prática, tendo discutido criticamente estes assuntos. Todavia, foram encontrados erros conceituais sobre sustentabilidade, conservação de massa, $\mathrm{pH}$ e resíduos (Quadro 8).

No levantamento das concepções prévias obtidas pelos mapas conceituais (Figura 2), percebemos que os alunos fizeram associação da temática biomassa com a proposta de reações químicas, e as trocas de energia observada nestes fenômenos. Encontramos, tanto nos mapas conceituais como nos questionários, conceitos relacionados com a química ambiental, tema que não foi trabalhado pela professora em sala de aula. Segundo Moreira (2011), os alunos provavelmente possuem subsunçores em sua estrutura cognitiva, que são conhecimentos e conceitos obtidos por experiências vividas, tanto na escola em outras disciplinas ou fora dela. Os conteúdos referentes a termoquímica e cinética química, abordados no segundo ano do Ensino Médio, também foram relatados, apesar dos mesmos não terem vivenciado este conteúdo em sala de aula. 
Quadro 8-Erros conceituais observados

\begin{tabular}{|c|c|c|c|}
\hline $\begin{array}{l}\text { Subcategoria } \\
\text { (Conceitual) }\end{array}$ & $\begin{array}{l}\text { Número de } \\
\text { menções }\end{array}$ & Grupos & $\begin{array}{l}\text { Extratos de textos } \\
\text { representativos apontados } \\
\text { (Unidades de Sentido) }\end{array}$ \\
\hline Inflamabilidade & 1 & $\mathrm{G} 2$ & $\begin{array}{l}\text { [o resíduo e a fumaça não são } \\
\text { inflamáveis, sólido e frágil] }\end{array}$ \\
\hline Reações Químicas & 1 & G1 & $\begin{array}{l}\text { [libera fumaça em uma reação de } \\
\text { decomposição] }\end{array}$ \\
\hline $\mathrm{pH}$ & 1 & G7 & $\begin{array}{l}\text { [o resíduo possui propriedades } \\
\text { básicas, e isso ocorre porque as } \\
\text { cinzas contêm um sal o carbonato } \\
\text { de sódio] }\end{array}$ \\
\hline Sustentabilidade & 5 & $\begin{array}{l}\mathrm{G} 1 ; \mathrm{G} 3 ; \mathrm{G} 4 \\
\mathrm{G} 6 ; \mathrm{G} 9\end{array}$ & $\begin{array}{l}\text { [por liberar muito } \mathrm{CO}_{2} \text { não é } \\
\text { sustentável] } \\
\text { [este processo não é sustentável } \\
\text { visto que produz muito gás } \\
\text { carbônico, o que contribui para o } \\
\text { efeito estufa] }\end{array}$ \\
\hline
\end{tabular}

Fonte: Autora (2019).

Sabemos que a assimilação de conceitos é um processo contínuo, pois o conhecimento é multifacetado e evolui constantemente, ou seja, "o processo de aprendizagem do conhecimento nunca está acabado" (DELORS, 2003, p. 92). Sob outra perspectiva, apesar de praticamente todos os grupos terem dado ênfase às questões ambientais, observaram-se erros conceituais relacionados a questões CTSA (Quadro 8). Este fato reitera a importância de se trabalhar com temáticas como esta, aqui proposta, em sala de aula (MARCONDES et al., 2016; SANTOS, 2008). Ao analisar os erros conceituais apontados no Quadro 8, a categoria sustentabilidade apresentou um maior número de erros, ou seja, dos 15 grupos analisados, 5 cometeram erros com relação a essa categoria. Por exemplo "por liberar muito $\mathrm{CO}_{2}$ não é sustentável", mostrando a necessidade de atividades envolvendo discussões com esses tópicos.

Evidências de aprendizagem significativa foram observadas pela aplicação de conteúdos conceituais e procedimentais em outros contextos (MOREIRA, 2011) durante esta SEI. Ao verem o bagaço de cana-de-açúcar pegando fogo, os estudantes associaram os conteúdos e as práticas experimentais vivenciadas previamente, como, por exemplo, as menções nos relatórios sobre a Lei da Conservação de Massas, Propriedades Periódicas, Reações Químicas, entre outros. Além disso, quando se depararam com os recursos fornecidos, como o papel indicador de $\mathrm{pH}$, fizeram a associação e mensuraram o pH da fumaça e das cinzas, uma vez que já haviam utilizado esse recurso em outro momento. Desta maneira, praticamente todos os grupos realizaram medidas de $\mathrm{pH}$ (Quadro 6), além de mencionarem nos mapas conceituais, a presença de substâncias ácidas, citando a chuva ácida (Figura 2).

Marcondes et al. (2016) reitera a importância de atividades práticas contextualizadas como a aqui detalhada. Existe um potencial considerável da biomassa como geradora de energia. Tecnologias estão sendo cada vez mais 
desenvolvidas priorizando-se uso de produtos oriundos de biomassa como combustíveis e para produção de energia elétrica. Socialmente, a produção de biomassa ocorre na zona rural, onde temos grande quantidade de pessoas com baixa renda e escolaridade. Outro exemplo de impacto social dentro desta temática são as carvoarias clandestinas e seu trabalho informal, atividade que causa enormes prejuízos na saúde dos trabalhadores.

É preciso discutir, com os alunos, quais os destinos apropriados da biomassa, e como esta pode contribuir para o desenvolvimento econômico, social e ambiental. A SEI detalhada neste trabalho é um exemplo de como propor atividades que oferecem ao aluno uma visão que vai além de conhecimentos científicos (CARVALHO; GIL-PÉREZ, 1995). Bazzo (1998) corrobora relatando que o cidadão merece entender a ciência e a tecnologia com suas implicações e consequências, para poder ser sujeito participante nas decisões de ordem política, social e ambiental, que certamente influenciarão o seu futuro e de seus descendentes.

\section{CONCLUSÕES}

O objetivo dessa pesquisa foi levantar quais conceitos químicos e concepções do movimento CTSA são aprendidos pelos alunos em uma SEl tendo a Biomassa como tema gerador. Inicialmente, levantamos as concepções e conhecimentos prévios dos alunos por meio de mapas conceituais, sendo esta etapa a norteadora para a elaboração das questões problematizadoras propostas no decorrer da atividade experimental. Pudemos observar que a SEI abarcou conteúdos conceituais, procedimentais e atitudinais, e que o estudante desempenhou um papel ativo na construção do conhecimento. Além disso, a SEI possibilitou, aos alunos, retomarem conteúdos específicos em química que foram úteis no levantamento de hipóteses e planejamento das atividades experimentais, produzindo, também, o levantamento de concepções prévias sobre diversos temas a serem estudados

Observamos que essa temática despertou o interesse dos alunos, que se apropriaram do problema, provavelmente porque a região onde moram é grande produtora de etanol a partir da cana-de-açúcar. Além disso, no decorrer da atividade e das discussões, os estudantes constataram que a biomassa, também conhecida por lixo agrícola, pode ser aproveitada, ponderando as vantagens e desvantagens das termoelétricas, por exemplo. Durante o experimento, perceberam que, apesar de produzir energia, a queima da biomassa gera gases nocivos e resíduos básicos. A partir de um experimento com elevado grau de abertura, tiveram oportunidade de observar fenômenos naturais, levantando hipóteses e, assim, se alfabetizando cientificamente. A SEI resultou em discussões frutuosas, no que diz respeito ao uso da biomassa, envolvendo questões do movimento CTSA. Práticas como esta estão alinhadas com a BNCC, que propõe um aumento de diálogo entre os conteúdos e o mundo real, bem como suas possibilidades de análises e de intervenções aplicadas a contextos mais amplos e complexos. Citam a temática matrizes energéticas, abarcando conceitos envolvidos em obtenção e transformações de energia, bem como as propriedades dos materiais. Desta maneira, o aluno pode se descobrir como membro ativo da sociedade, tornando-se um indivíduo que pode fazer a diferença. 


\title{
INVESTIGATIVE TEACHING SEQUENCES IN STSE APPROACH: BIOMASS AS A THEME OF LEARNING PROCESS OF CHEMICAL CONCEPTS
}

\begin{abstract}
In this essay, we share the results of the application of an Investigative Teaching Sequence (ITS), for two classes in the first year of high school, having Biomass as the theme. We will present how ITS promoted the reapprochement of specific Chemistry contents, promoting fruitful discussions on STSE (Science, Technology, Society and Environment) issues and reflections about the solid residues generated by the sugar and alcohol factories, so common in the region where the students live. Concept maps were used to survey previous conceptions and guide the proposed questions. From experimental apparatus and a mini boiler previously built with low-cost materials, groups of students were able to raise hypotheses, plan and carry out their experiments. The systematization of the information was based on reports, and the analysis of the content of the reports resulted in six categories, of which five brought together specific content in chemistry and one grouped issues related to the STSE. We know the need to promote discussions with our students, about possible sources of clean and sustainable energy, and we observe that the Biomass theme was assertive in this sense, supporting at the integral education of the students. In addition, this work shows the need to rethink the chemistry curriculum, since the specific contents should not be treated in a linear manner.
\end{abstract}

KEYWORDS: Chemistry teaching. Inquiry. Didactic sequence. 


\section{NOTAS}

1 Disponível em: http://gbio.webhostusp.sti.usp.br.

2 Disponível em: https://cmap.ihmc.us.

3 Disponível em: http://g1.globo.com/jornal-da-globo/noticia/2014/10/biomassaja-responde-por-quase-10-de-toda-matriz-energetica-do-brasil.html.

\section{REFERÊNCIAS}

BAZZO, W. A. Contexto da Educação Tecnológica. Ciência, Tecnologia e Sociedade. Florianópolis: Editora UFSM, 1998.

BARDIN, L. Análise de conteúdo. São Paulo: Edições 70, 2011.

BORGES, F. R. F. D.; BENETTI, L. B. Educação Ambiental: uma abordagem através de gêneros textuais a partir de oficinas de leitura e produção de textos. Revista Monografias Ambientais, v. 14, n. especial, p. 52- 64, 2015.

BRASIL. Ministério da Educação. Base Nacional Comum Curricular. Brasília: Ministério da Educação, 2017. Disponível em: http://basenacionalcomum.mec.gov.br/abase/\#medio/ciencias-da-natueza-esuas-tecnologias-no-ensino-medio-competencias-especificas-e-habilidades. Acesso em: 13 dez. 2018.

CAÑAL, P. El diseño de unidades didacticas: fundamentacion y procedimientos. In: CAÑAL, P.; LLEDÓ, A. I.; POZUELOS, F. J.; TRAVÉ, G. (Orgs.). Investigar em la escuela: elementos para una enseñanza alternativa. Sevilla: Díada, 1997, p. 109132.

CARVALHO, A. M. P. O ensino de Ciências e a proposição de sequências de ensino investigativas. In: CARVALHO, A. M. P. (Org.). Ensino de Ciências por Investigação: condições para implementação em sala de aula. São Paulo: Cengage, 2018, p. 1-20.

DELORS, J. Educação: um tesouro a descobrir. 2. ed. São Paulo: Cortez, 2003. 
GOUVEIA, N. Resíduos Sólidos urbanos: impactos socioambientais e perspectivas de manejo sustentável com inclusão social. Ciência e Saúde Coletiva, v. 17, n. 6, p. 1503 - 1510, jun. 2012.

GBIO. Importância e vantagens da biomassa. Grupo de Pesquisa em Bioenergia, 2019. Disponível em: <http://gbio.webhostusp.sti.usp.br/?q=pt-br>. Acesso em: 20 jun. 2019.

INSTITUTO DE ECONOMIA AGRÍCOLA. Cana-de-açúcar: geração de bioeletricidade nas usinas do Protocolo Agroambiental Paulista. In: INSTITUTO DE ECONOMIA AGRíCOLA. Boletim Do Instituto De Economia Agrícola (IEA), n. 20, maio 2017. Disponível em: http://www.iea.sp.gov.br/out/boletim/n20.pdf. Acesso em: mai. 2018.

MARCONDES, M. E. R. et al. Materiais instrucionais numa perspectiva CTSA: uma análise de unidades didáticas produzidas por professores de química em formação continuada. Investigações em Ensino de Ciências, v. 14, n. 2, p. 281298, 2016.

MOTOKANE, M. T. Sequências didáticas investigativas e argumentação no ensino de ecologia. Ensaio: Pesquisa em Educação em Ciências, v. 17, n. especial, p. 115-137, 2015.

MOREIRA, M. A. Aprendizagem significativa: a teoria e texto complementares. São Paulo: Editora Livraria da Física, 2011.

NOVAK, J. D. Meaningful learning: the essential factor for conceptual change in limited or inappropriate propositional hierarchies leading to empowerment of learners. Science Education, Hoboken, v. 86, n. 4, p. 548-571, 2002.

RAMOS, R. C.; NACHILUK, K. Geração de Bioenergia de Biomassa da Cana-deaçúcar nas Usinas Signatárias ao Protocolo Agroambiental Paulista, Safra 2015/2016. Instituto De Economia Agrícola, São Paulo, v. 12, n. 4, abr. 2017. Disponivel em: http://www.iea.sp.gov.br/out/LerTexto.php?codTexto=14278. Acesso em: mai. 2018.

SANTOS, W. L. P. Contextualização no ensino de ciências por meio de temas CTS em uma perspectiva crítica. Ciência e Ensino, v. 1, 2008.

SANTOS, W. L. P.; MORTIMER, E. F. Tomada de decisão para ação social responsável no ensino de ciências. Ciência \& Educação, v. 7, n. 1, p. 95111, 2001. 
SANTOS, W. L. P.; SCHNETZLER, R. P. Educação em Química: um compromisso com a cidadania. ljuí: Unijuí, 1997.

SANTOS, W. L. P.; GALIAZZI, M. C.; PINHEIRO JUNIOR, E. M.; SOUSA, M. L.; PORTUGAL, S. O Enfoque CTS e a Educação Ambiental: Possibilidade de "Ambientalização" na Sala de Aula de Ciências. In: SANTOS, W. L. P.; MALDANER, O. A. (Orgs.). Ensino de Química em Foco. ljuí: Unijuí, 2015, p. 131-158.

SANTOS, W. L. P.; MORTIMER, E. F. Uma análise de pressupostos teóricos da abordagem CTS (Ciência - Tecnologia - Sociedade) no contexto da educação brasileira. Ensaio Pesquisa em Educação em Ciências, v. 2, n. 2, p. 110-132, dez. 2000.

TRIGUEIRO, A. Biomassa já responde por quase $10 \%$ de toda a matriz energética do Brasil. Jornal da Globo, 29 out. 2014. Disponível em: http://g1.globo.com/jornal-da-globo/noticia/2014/10/biomassa-ja-respondepor-quase-10-de-toda-matriz-energetica-do-brasil.html. Acesso em: 17 out. 2018.

Recebido: 04 out. 2019.

Aprovado: 15 abr. 2020

DOI: $10.3895 /$ rbect.v13n3.10923

Como citar: MAGALHÃES, P. P; BIGHETTI, R. C.; LEGENDRE, A. O.; ZULIANI, S. R. Q. A. Sequências de ensino investigativas envolvendo CTSA: a biomassa como tema gerador do processo de aprendizagem de conceitos químicos. Revista Brasileira de Ensino de Ciência e Tecnologia, Ponta Grossa, v.13, n. 3, p. 281-299, set/dez. 2020. Disponível em: <https://periodicos utfpr edu.br/rbect/article/view/10923>. Acesso em: XXX.

Correspondência: Prislaine Pupolin Magalhães - prislaine.magalhaes@unesp.br

Direito autoral: Este artigo está licenciado sob os termos da Licença Creative Commons-Atribuição 4.0 Internacional. 